\title{
Utilization of Lapindo Volcanic Mud for Enhanced Sono- sorption Removal of Acid Orange 52
}

\author{
Nur Hidayatul Nazirah Kamarudin 1,2,*, Herma Dina Setiabudi' ${ }^{3}$, Aishah Abdul Jalil ${ }^{4}$, Siti \\ Hazirah Adam ${ }^{5}$, Nur Fatien Muhamad Salleh ${ }^{6}$
}

${ }^{1}$ Centre for Sustainable Process Technology (CESPRO), Faculty of Engineering and Built Environment, Universiti Kebangsaan Malaysia, 43600 UKM Bangi, Selangor, Malaysia

${ }^{2}$ Chemical Engineering Programme, Faculty of Engineering and Built Environment, Universiti Kebangsaan Malaysia, 43600 UKM Bangi, Selangor, Malaysia

${ }^{3}$ Faculty of Chemical \& Natural Resources Engineering, Universiti Malaysia Pahang, Lebuhraya Tun Razak, 26300 Gambang, Kuantan, Pahang, Malaysia

${ }^{4}$ Department of Chemical Engineering, Faculty of Chemical and Energy Engineering, Universiti Teknologi Malaysia, 81310 UTM Johor Bahru, Johor, Malaysia

${ }_{5}^{5}$ Department of Chemical Engineering and Energy Sustainability, Faculty of Engineering, Universiti Malaysia Sarawak, 94300 Kota Samarahan, Sarawak, Malaysia

${ }^{6}$ Environmental and Occupational Health Programme, School of Health Sciences, Health Campus, Universiti Sains Malaysia, 16150 Kubang Kerian, Kelantan, Malaysia

Received: 1st October 2018; Revised: 22nd December 2018; Accepted: $7^{\text {th }}$ January 2019; Available online: $25^{\text {th }}$ January 2019; Published regularly: April 2019

\section{Abstract}

This study applied ultrasonic irradiation technique to remove acid orange 52 (AO52) and in the meantime utilizing the potential adsorbent, Lapindo volcanic mud (LVM). LVM was collected from the erupted mud in Sidoarjo, Indonesia and calcined prior the adsorption process. Previously in another study, Lapindo was proven to be efficient for adsorption of dyes in single adsorption method. In this study, the combination of adsorption with ultrasound, or as known as sono-sorption shows that the adsorptivity increased from $95.54 \mathrm{mg} / \mathrm{g}$ to $129.5 \mathrm{mg} / \mathrm{g}$. The isotherm study shows that this process obeyed Langmuir isotherm model with adsorption capacity of $833.33 \mathrm{mg} / \mathrm{g}$. The enhancement of sono-sorption method as compared to conventional method is believed to be resulted from the facilitated mass transfer driven by the ultrasound, along with the adsorption ability of LVM. The kinetic study fit to the pseudo second order equation. Copyright (C) 2019 BCREC Group. All rights reserved

Keywords: Methyl orange; Lapindo volcanic mud; Ultrasonic irradiation; Adsorption

How to Cite: Kamarudin, N.H.N., Setiabudi, H.D., Jalil, A.A., Adam, S.H., Salleh, N.F.M. (2019). Utilization of Lapindo Volcanic Mud for Enhanced Sono-sorption Removal of Acid Orange 52. Bulletin of Chemical Reaction Engineering \& Catalysis, 14 (1): 189-195 (doi:10.9767/bcrec.14.1.3326.189-195)

Permalink/DOI: https://doi.org/10.9767/bcrec.14.1.3326.189-195

\section{Introduction}

Acid orange 52 is widely used in the food industries, dyestuff manufacturing, paper manu-

* Corresponding Author.

Email: nhnazirah@ukm.edu.my (N.H.N. Kamarudin), Telp: +6-03-89217138, Fax: +6-03-89118345 facturing, textile, printing, and also as $\mathrm{pH}$ indicator [1]. However, this compound is considerably toxic to the aquatic life as it is being discharged to the water system. There were many research dedicated to the water system concerning the dyestuff toxicity, contributing to the development of various method of treatments. Among them, adsorption method is seen as 
highest potential because of its economic feasibility, flexibility, and efficiency. Meanwhile, the utilization of ultrasound for dyes and pollutants removal from water over the past two decades has received much attention by worldwide researcher owing to their potential to enhance the removal efficiency of dyes and pollutants [3-6]. Ultrasound basically employed acoustic cavitation that formed bubbles that vibrated along the medium [3,7]. In accordance, the mass transfer from adsorbate bulk to the adsorbent surface which typically restrict effectiveness of adsorbent could be improved greatly [8]. From previous studies, there have been several reports utilizing the sono-sorption along with adsorbents for wastewater treatment. Li et al. utilized exfoliated graphite to adsorb azo dye, which was enhanced with the presence of ultrasound [9]. In addition, similar trends were observed by M.H. Entezari et al., in which the elimination of Remazol black B from simulated waste solution was greatly enhanced upon the combination ultrasound and adsorption method [10].

Among the researched adsorbents, activated carbon shown outstanding performance of high adsorptivity despite being high cost. Therefore, many study on finding less cost adsorbent had been conducted, which used fly ash [11], sawdust [12], waste sludge [13], waste newspaper [14] and seed husks [15]. Clay minerals such as bentonite [16], montmorillonite [17], kaolin [18] and sepiolite [19] also have drawn much attention in recent years due to their high chemical stabilities, high surface area, functionalizable surfaces and structural properties [20].

Lapindo mud is a type of volcanic mud which erupted in May 2006, located in Sidoarjo, Indonesia that has been in eruption since May 2006. The latest known flow rate of the erupted mud is about $80,000 \mathrm{~m}^{3 /}$ day and nothing could possibly stop them for more years to come [21]. Therefore, finding a profitable uses for the mud, could be advantageous from the economical and environmental perspective.

Previously, we had investigated the ability of the calcined LVM for the same purpose in conventional method [22]. To date, there were no reports done on using the combination of Lapindo volcanic mud with ultrasound, thus we attempt to identify the synergistic effect of both. This is also due to the assumption that the ultrasound could possibly agglomerate or the LVM that could resulted in reduced surface area. The effects of several parameters on adsorption capacity were also studied along with isotherm and kinetics study.

\section{Materials and Methods}

\subsection{Materials}

AO52, with chemical name Sodium $p$ dimethylamino-azobenzesulphonate (Molecular formula $\mathrm{C}_{14} \mathrm{H}_{14} \mathrm{~N}_{3} \mathrm{NaO}_{3} \mathrm{~S}$; Molecular weight 327.33) was procured from Merck and was used as received. The dye solution was prepared at the desired concentration using MilliQ water. Adsorbent, Lapindo volcanic mud (LVM), was obtained from Sidoarjo, Indonesia in the form of grey-colored clay. The LVM was treated according to the procedure for washedcalcined LVM described in previous report [22]. It was calcined at $550{ }^{\circ} \mathrm{C}$ prior to use to remove water and hydrocarbons. LVM was sieved by using a sieve set and then was collected in the range of 104 and $150 \mathrm{~m}$. The specific surface area was $45.59 \mathrm{~m}^{2} / \mathrm{g}$.

\subsection{Experiments}

The adsorption experiments of AO52 on LVM without ultrasonic irradiation were carried out in batch mode according to the method describe in previous report [22]. In short, a 200 $\mathrm{ml}$ volume of AO52 solution, previously adjusted to a fixed $\mathrm{pH}$ value was added to a 250 $\mathrm{mL}$ beaker containing different amount of LVM. The mixture was stirred magnetically at room temperature and $300 \mathrm{rpm}$.

The sono-sorption (adsorption with ultrasonic irradiation) experiments were accomplished with ultrasonic cleaner bath (Bransonic $5510 \mathrm{E}-\mathrm{DTH}$, with a frequency of $40 \mathrm{kHz}$, and a nominal power of $185 \mathrm{~W}$ ). $200 \mathrm{ml}$ of AO52 solution (various concentrations) was contained in a $250 \mathrm{~mL}$ Erlenmeyer flask and immersed in the bath. The $\mathrm{pH}$ of the solution was adjusted with $0.1 \mathrm{M} \mathrm{HCl}$ or $0.1 \mathrm{M} \mathrm{NaOH}$ solution. The temperature was controlled at room temperature by a circulating bath. A desired amount of LVM was added to the AO52 solution and simultaneously the ultrasonic power was turned on.

For both methods, samples were withdrawn from Erlenmeyer flask at pre-determined time intervals until the adsorption equilibrium was reached. Next, samples were centrifuged and filtered according to the method described in the literature [22]. In brief, samples were centrifuged at 13,200 rpm for $20 \mathrm{~min}$ and the supernatants were filtered using a Millex-NH filter (Millipore $0.45 \mathrm{~mm}$ ). Each experiment was replicated three times. 


\subsection{Dye Concentration and Removal Capacity}

The concentration of the dye was measured using a UV-vis spectrophotometer (Genesys 10 UV/Vis Scanning, Thermo Electron, UK). The measurements were made at a wavelength of $478 \mathrm{~nm}$, which corresponds to the maximum absorbance.

The adsorption capacity of the dye $(q)$ was calculated according to Equation (1).

$$
q=\left(C_{i}-C_{e}\right) \times \frac{V}{m}
$$

where $C_{i}$ is the initial AO52 concentration $(\mathrm{mg} / \mathrm{L}), C_{e}$ is the AO52 concentration at the adsorption equilibrium $(\mathrm{mg} / \mathrm{L}), V$ is the volume of A052 solution (L), and $m$ is the weight of the LVM (g). The percentage of dye adsorbed $(\% d)$ was determined by Equation (2).

$$
\% d=\frac{\left(C_{i}-C_{e}\right)}{C_{i}} \times 100
$$

\subsection{Isotherm Study}

The equilibrium isotherms, Langmuir [23] and Freundlich [24] isotherms were applied in this study. The Langmuir model had been linearized as follows:

$$
\frac{1}{q_{e}}=\frac{1}{q_{m}}+\frac{1}{q_{m} K_{L}} \frac{1}{C_{e}}
$$

where $q_{e}$ is the amount of AO52 adsorbed per unit of adsorbent at equilibrium $(\mathrm{mg} / \mathrm{g}), C_{e}$ is the concentration of dye solution at equilibrium $(\mathrm{mg} / \mathrm{L}), q_{m}$ is the maximum amount of adsorption with complete monolayer coverage on the adsorbent surface (mg/g), and $K_{L}$ is the Langmuir constant, which is related to the energy of adsorption (L/mg). The Langmuir constant $q_{m}$

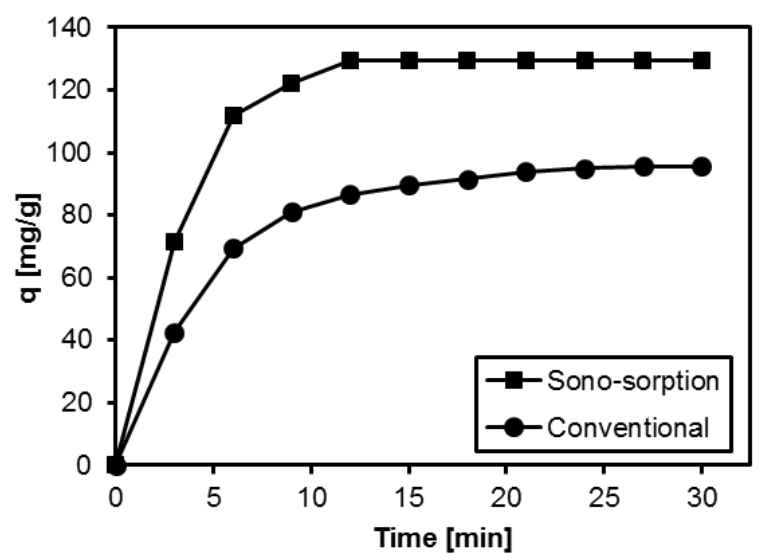

Figure 1. Effect of sono-sorption method on adsorption capacity (initial concentration 100 $\mathrm{mg} / \mathrm{L}$, adsorbent dosage $0.5 \mathrm{~g} / \mathrm{L}$, initial $\mathrm{pH} 3$ ). and $K_{L}$ can be determined from the intercept and the slope of the linear plot of $1 / q_{e}$ versus $1 / C_{e}$

The Freundlich isotherm is an empirical equation employed to describe heterogeneous system, and had been simplified in linear form as follows:

$$
\log q_{e}=(1 / n) \log C_{e}+\log K_{f}
$$

where $q_{e}$ is the amount of AO52 adsorbed per unit of adsorbent at equilibrium $(\mathrm{mg} / \mathrm{g}), C_{e}$ is the concentration of dye solution at equilibrium $(\mathrm{mg} / \mathrm{L}), K_{f}$ and $n$ are the Freundlich adsorption isotherm constant, which indicate the extent of the adsorption and the degree of nonlinearity between solution concentration and adsorption, respectively. The values of $K_{f}$ and $1 / n$ can be determined from the intercept and the slope of the linear plot of $\log q_{e}$ versus $\log$ $C_{e}$.

\subsection{Kinetics Study}

The adsorption kinetics of AO52 onto LVM were analysed by using pseudo-first-order and pseudo-second-order kinetic models. Pseudofirst-order model is based on the assumption that the rate of change of solute uptake over time is directly proportional to the difference in saturation concentration and the amount of solid uptake over time. The pseudo-first order model was presented by Lagergren [25] and had been simplified to the form of:

$$
\log \left(q_{e}-q_{t}\right)=\log q_{e}-\frac{k_{1}}{2.303} t
$$

where $q_{e}$ and $q_{t}$ are the amount of A052 adsorbed per unit of adsorbent ( $\mathrm{mg} / \mathrm{g})$ at equilibrium, and at time $t$, respectively and $\mathrm{k}_{1}$ is the pseudo-first-order rate constant $\left(\mathrm{min}^{-1}\right)$. The rate constant, $k_{1}$ was obtained from slope of the linear plots of $\log \left(q_{e}-q_{t}\right)$ against $t$.

The pseudo-second-order model is expressed as follows by Ho and McKay [26] and had been simplified in the form as follows:

$$
\frac{t}{q_{t}}=\frac{1}{k_{2} q_{e}^{2}}+\frac{t}{q_{e}}
$$

where $k_{2}$ is the pseudo-second-order rate constant (g/mg.min).

\section{Results and Discussion}

\subsection{Combination with Ultrasound}

According to Figure 1, presence of ultrasound increased the adsorptivity of AO52 on LVM from 95.54 to $129.5 \mathrm{mg} / \mathrm{g}$. In addition, the time interval to achieve maximum adsorption 
capacity became faster in the presence of ultrasound, from $27 \mathrm{~min}$ reduced to $12 \mathrm{~min}$ of contact time, which is possibly attributed to the rupture of LVM particles due to ultrasonic irradiation which consequently decrease the particle size of LVM and increase the surface area that is accessible for adsorption [27]. Thus, the introduction of ultrasound lead to the increase in adsorption capacity. The similar result was observed for the removal of AO52 with activated aluminas under sonochemical methods reported by Lida et al. which mentioned that the action of ultrasound resulted to the enhancement of the mass transfer [8].

\subsection{Variation of $\mathrm{pH}$}

Figure 2 presented the effect of $\mathrm{pH}$ variation on the LVM's adsorptivity under sonochemical method at a $\mathrm{pH}$ range of 3-10 is shown. Accordingly, when the $\mathrm{pH}$ increased, the adsorption capacity decreased significantly. Based on the

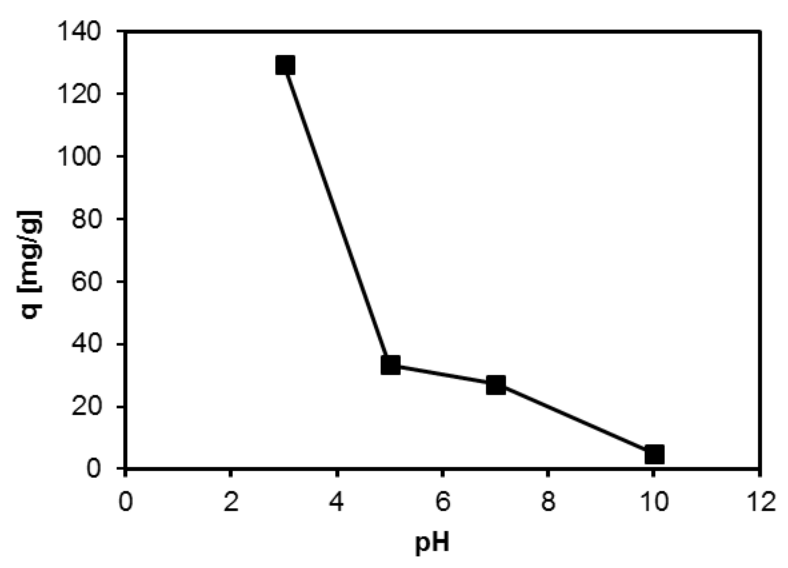

Figure 2. Effect of $\mathrm{pH}$ on adsorption capacity (initial concentration $100 \mathrm{mg} / \mathrm{L}$, adsorbent dosage $0.5 \mathrm{~g} / \mathrm{L}$ ).

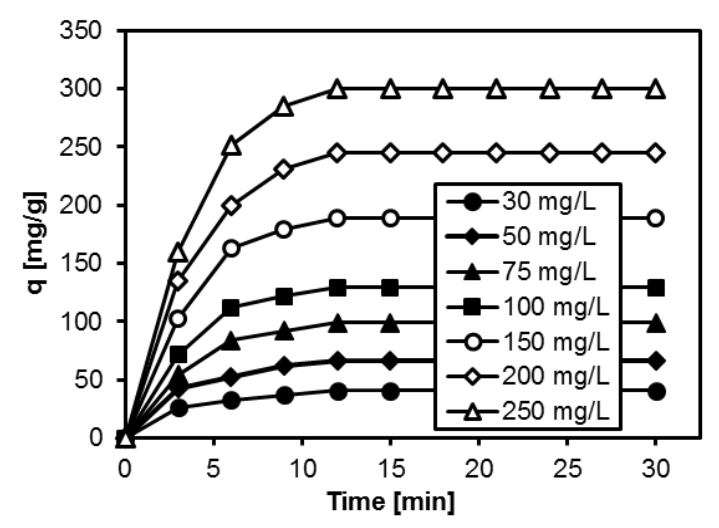

Figure 3. Effect of initial concentration on adsorption capacity (adsorbent dosage 0.5 $\mathrm{g} / \mathrm{L}$, initial $\mathrm{pH}$ 3). previous report [22], LVM structure consist of mainly $\mathrm{SiO}_{2}$ and $\mathrm{Al}_{2} \mathrm{O}_{3}$. At low $\mathrm{pH}$ value, silica were protonated to give $\mathrm{Si}^{4+}$ and resulting more active LVM surface for adsorption process whereas $\mathrm{Al}_{2} \mathrm{O}_{3}$ were dissolved in strong acid to form $\mathrm{Al}^{3+}$. This aluminium cation assist the AO52 anion diffusion to the adsorbent surface. In this study, maximum adsorptivity was observed at $\mathrm{pH} 3$ in which the pattern decreased drastically when the $\mathrm{pH}$ was increased to 5 . This is also in accordance with our previous study using LVM without the ultrasound [22].

\subsection{Variation of Initial AO52 Concentration}

The effect of various initial concentration is presented in Figure 3. The adsorption capacity of AO52 increased from 40.8 to $300.2 \mathrm{mg} / \mathrm{g}$ with the increasing of AO52 initial concentration. As the mass transfer driving force increases, greater amount of AO52 was adsorbed alongwith higher initial dye concentration due the reduced adsorbate uptake resistance. Higher concentration of solution resulted to the higher adsorption. This result is in correspondence with our previous work, which stated that the adsorptivity of $\mathrm{AO} 52$ was directly relative to the initial AO52 concentration [22].

\subsection{Effect of LVM Dosage}

According to Figure 4, percentage removal of AO52 increased with the LVM dosage, whereas the adsorption capacity was decreased. In fact, a greater number of possible binding sites for adsorption process should be increase as the adsorbent dosage increased. In contrast, adsorption capacity decreased since the unit of the adsorption capacity was milligram of adsorbate per mass (g) of LVM. In accordance, a higher absorbent dosage exposed

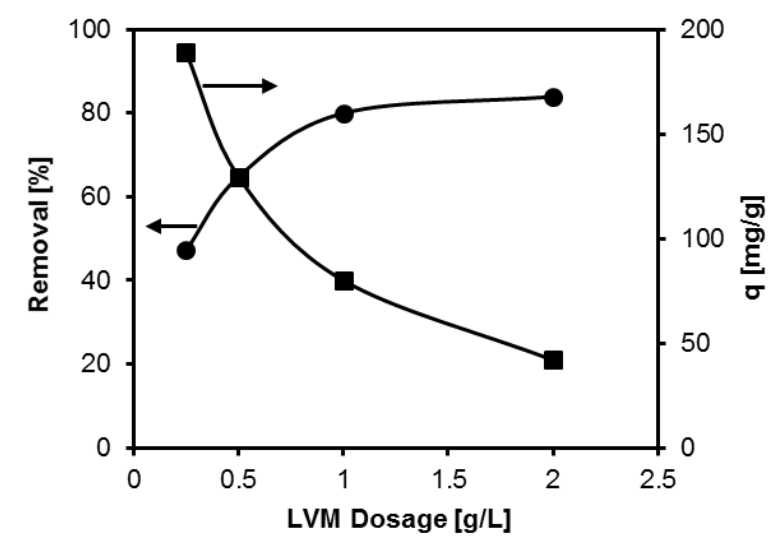

Figure 4. Effect of LVM dosage on adsorption capacity and removal percentage (initial concentration $100 \mathrm{mg} / \mathrm{L}$, initial pH 3). 
more surface site for adsorption. For the same amount of adsorbate with higher adsorbent dosage, more surface site is offered thus more adsorption sites remain unoccupied, thus resulted to lower adsorption capacity [22]. By considering the values of percentage removal

Table 1. Isotherm parameters for adsorption of AO52 on LVM under sono-sorption method at $30^{\circ} \mathrm{C}$.

\begin{tabular}{lc}
\hline \multicolumn{1}{c}{ Isotherm } & Parameters \\
\hline Langmuir & \\
$q_{m}(\mathrm{mg} / \mathrm{g})$ & 833.33 \\
$K_{L}(\mathrm{~L} / \mathrm{mg})$ & 0.00534 \\
$R^{2}$ & 0.9997 \\
$R_{L}$ range & $0.4284-0.8620$ \\
& \\
Freundlich & \\
$K_{f}$ & 6.1306 \\
$1 / n$ & 0.8506 \\
$R^{2}$ & 0.9990 \\
\hline
\end{tabular}

and adsorption capacity, optimum adsorption dosage was observed at $0.5 \mathrm{~g} / \mathrm{L}$. Thus, all further studies were carried out at this adsorbent dosage.

\subsection{Adsorption isotherms}

The adsorption isotherm was calculated and plotted accordingly as in Section 2.4 (Figure 5 and Table 1). It's appeared that the adsorption of AO52 obeyed the Langmuir model, based on the $R^{2}$ values. This result demonstrated that the adsorption of AO52 formed monoloyer process on the surface of LVM. This result is in correspondence with our previous work, for the adsorption onto LVM without the ultrasound [22]. However, the values of adsorption capacity $\left(q_{m}\right)$ in current study is higher $(833.33 \mathrm{mg} / \mathrm{g})$ than prior method $(333.33 \mathrm{mg} / \mathrm{g})$ as discussed in the previous section. As it was explained, the presence of ultrasound increased the surface area available for reaction and facilitated the contact between LVM and AO52 molecule.

Table 2. Adsorption kinetic parameters for the adsorption of AO52 on LVM under sono-sorption method at different initial temperatures.

\begin{tabular}{|c|c|c|c|c|c|c|c|c|}
\hline \multirow{2}{*}{$\begin{array}{c}C_{o} \\
(\mathrm{mg} / \mathrm{L})\end{array}$} & \multirow[b]{2}{*}{$\begin{array}{c}q_{e}, \exp \\
(\mathrm{mg} / \mathrm{g})\end{array}$} & \multicolumn{3}{|c|}{ Pseudo-first order } & \multicolumn{4}{|c|}{ Pseudo-second order } \\
\hline & & $\begin{array}{c}q_{e} \\
(\mathrm{mg} / \mathrm{g})\end{array}$ & $\begin{array}{c}k_{1} \\
(1 / \mathrm{min})\end{array}$ & $\mathrm{R}^{2}$ & $\begin{array}{c}q_{e} \\
(\mathrm{mg} / \mathrm{g})\end{array}$ & $\begin{array}{c}k_{2} \\
\text { (g/mg.min) }\end{array}$ & $\mathrm{R}^{2}$ & $\begin{array}{c}h \\
\text { (mg/g.min) }\end{array}$ \\
\hline 30 & 40.80 & 36.50 & 0.2579 & 0.9860 & 42.37 & 0.0245 & 0.9972 & 44.0529 \\
\hline 50 & 66.82 & 65.46 & 0.2909 & 0.9790 & 69.44 & 0.0148 & 0.9968 & 71.4286 \\
\hline 75 & 99.03 & 101.02 & 0.3005 & 0.9954 & 103.09 & 0.0090 & 0.9955 & 95.2381 \\
\hline 100 & 129.50 & 135.83 & 0.3247 & 0.9942 & 135.14 & 0.0073 & 0.9956 & 133.3333 \\
\hline 150 & 189.50 & 202.95 & 0.3280 & 0.9942 & 196.08 & 0.0049 & 0.9952 & 188.6792 \\
\hline 200 & 244.90 & 266.62 & 0.3169 & 0.9920 & 256.41 & 0.0035 & 0.9952 & 227.2727 \\
\hline 250 & 300.20 & 334.81 & 0.3339 & 0.9919 & 312.50 & 0.0029 & 0.9947 & 285.7143 \\
\hline
\end{tabular}
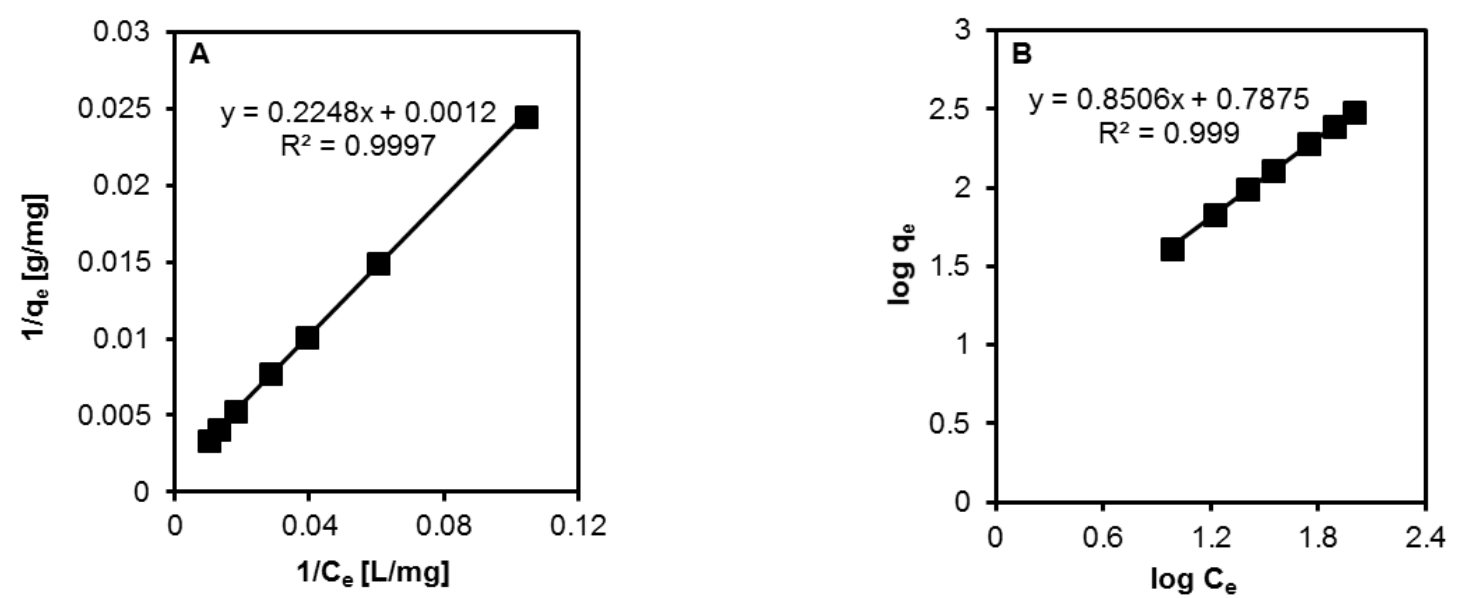

Figure 5. Adsorption isotherm (A) Langmuir and (B) Freundlich for adsorption of AO52 on LVM under sono-sorption method (initial concentration $100 \mathrm{mg} / \mathrm{L}$, adsorbent dosage $0.5 \mathrm{~g} / \mathrm{L}$, initial $\mathrm{pH} 3$ ). 

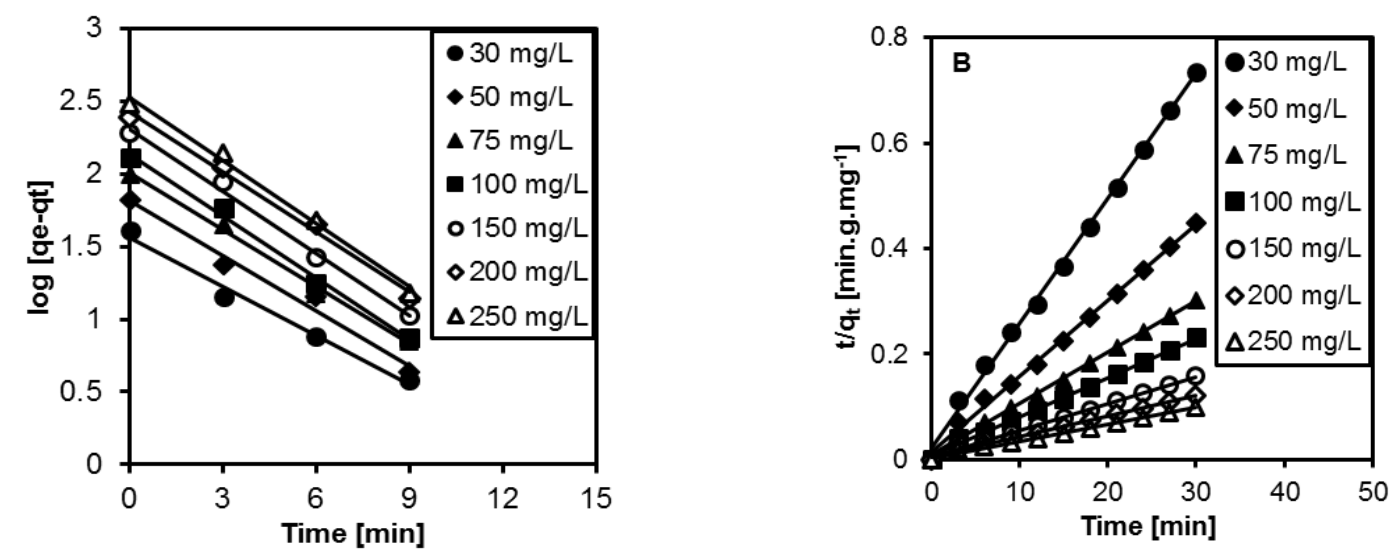

Figure 6. (A) Pseudo-first-order and (B) Pseudo-second-order kinetics for adsorption of AO52 on LVM under sono-sorption method (initial concentration $100 \mathrm{mg} / \mathrm{L}$, adsorbent dosage $0.5 \mathrm{~g} / \mathrm{L}$, initial $\mathrm{pH} 3$ ).

Since the values of $0<R_{L}<1$, the adsorption of AO52 on the surface of LVM is favourable at the temperature studied.

Enhancement in the adsorption process caused by the introduction of ultrasound was also observed on the adsorption of methylthioninium chloride (Swiss Blue) [14] in which the introduction of ultrasound increased the adsorptivity from 59 to $611 \mathrm{mg} / \mathrm{g}$.

\subsection{Adsorption Kinetics}

Table 2 presented the kinetic data, whereas, Figure 6 elucidates the linear plots for both models, of pseudo first-order and pseudo second-order kinetics for adsorption of AO52 on LVM under sono-sorption method. The linear plots of pseudo second-order kinetic model displayed the equivalent values of calculated and experimental $q_{e}$. Since the $R^{2}$ value is more than 0.9947, the adsorption process of AO52 on LVM under sono-sorption method is indicated to obey this kinetic model. This result is in correspondence with our previous work, for the adsorption of AO52 on LVM under conventional method [22]. However, the rate constants were higher in sono-sorption (0.0029-0.0245 g/mg.min) than conventional method (0.00140.0094 g/mg.min).

\section{Conclusion}

The current work investigated the elimination of AO52 by LVM in synergistic condition of sono-sorption. Sono-sorption condition increased the adsorption capacity of AO52 by $35.5 \%$ which is initially $95.54 \mathrm{mg} / \mathrm{g}$, to 129.5 $\mathrm{mg} / \mathrm{g}$, due to the enhancement of mass transfer which assist the adsorption of A052. The adsorption isotherm followed the Langmuir mod- els, demonstrating that the adsorption of AO52 on LVM occurs as a monolayer process. Kinetic studies showed that the adsorption of AO52 onto LVM followed the pseudo-second-order model. The higher adsorption capacity and faster removal of AO52 by the sono-sorption method by using an adsorbent of LVM could be employed as a method to remove pollutants, especially dyestuff in industrial water treatment due to the abundance and efficiencies of LVM.

\section{Acknowledgements}

The authors were thankful to the Ministry of Science, Technology and Innovation of Malaysia (MOSTI) for the financial supports under the Fundamental Research Grant Scheme (FRGS/1/2016/STG07/UKM/03/1).

\section{References}

[1] Chu, W., Ma., C.W. (2000). Quantitative prediction of direct and indirect dye ozonation kinetics, Water Res., 34: 3153-3160.

[2] Aksu, Z., Tezer, S. (2000). Equilibrium and kinetic modelling of biosorption of Remazol Black B by Rhizopus arrhizus in a batch system: effect of temperature, Process Biochem., 36: 431-439.

[3] Thompson, L.H., Doraiswamy, L.K. (1999). Sonochemistry: Science and Engineering, Ind. Eng. Chem. Res., 38: 1215-1249.

[4] Nagata, S. N., Nakagawa, M., Okuno, H., Mizukoshi, Y., Yim B., Maeda, Y. (2000). Sonochemical degradation of chloro-phenols in water, Ultrason. Sonochem., 7: 115-120.

[5] Wang, X., Yao, Z., Wang, J., Guo, W., G. Li. (2008). Degradation of reactive brilliant red in aqueous solution by ultrasonic cavitation, Ultrason. Sonochem., 15: 43-48. 
[6] Stępniak, L., Kępa, U., Stańczyk-Mazanek, E. (2009). Influence of a high-intensity ultrasonic field on the removal of natural organic compounds from water, Desal. Water Treat., 5: 29-33.

[7] Didenko, Y.T., McNamara III, W.B. Suslick, K.S. (1999). Hot spot conditions during cavitation in water, J. Am. Soc., 121: 5817-5818.

[8] Lida, Y., Kozuka, T., Tuziuti T., Yasui, K. (2004). Sonochemically enhanced adsorption and degradation of methyl orange with activated aluminas, Ultrasonics, 42: 635-639.

[9] Li, J.T., Li, J.H., Li, M., Sun, H.W. (2007). Decolorization of azo dye direct scarlet 4BS solution using exfoliated graphite under ultrasonic irradiation, Ultrason. Sonochem., 14: 241-245.

[10] Entezari, M.H., Al-Hoseini, Z.S., Ashraf, N. (2008). Fast and effiecient removal of Reactive Black 5 from aqueous solution by a combined method of ultrasound and sorption process, Ultrason. Sonochem., 15: 433-437.

[11] Fungaro, D.A., Bruno M., Grosche, L.C. (2009). Adsorption and kinetic studies of methylene blue on zeolite synthesized form fly ash, Desal. Water Treat., 2: 231-239.

[12] Ofomaja, A.E. (2009). Equilibrium sorption of methylene blue using mansonia wood sawdust as biosorbent, Desal. Water Treat., 3: 110 .

[13] Wang X.S., Lin, H.Q. (2011). Adsorption of basic dyes by dried waste sludge: Kinetic, equilibrium and desorption studies, Desal. Water Treat., 29: 10-19.

[14] Entezari, M.H., Al-Hoseini, Z.S. (2007). Sonosorption as a new method for the removal of methylene blue from aqueous solution, Ultrason. Sonochem., 14: 599-604.

[15] Franca, A.S., Oliveira, L.S., Saldanha, S.A., Santos P.I.A., Salum, S.S. (2010). Malachite green adsorption by mango (Mangifera indica L.) seed husks: Kinetic, equilibrium and thermodynamic studies. Desal. Water Treat., 19: 241-248.

[16] Bulut, E., Özacar, M., Şengil, I.A. (2008). Equilibrium and kinetic data and process design for adsorption of Congo Red onto bentonite, J. Hazard. Mater., 154: 613-622.
[17] Almeida, C.A.P., Debacher, N.A., Downs, A.J., Cottet, L., Mello, C.A.D. (2009). Removal of methylene blue from colored effluents by adsorption on montmorillonite clay, J. Colloid Interface Sci., 332: 46-53.

[18] Nandi, B.K., Goswami, A., Purkait, M.K. (2009). Removal of cationic dyes from aqueous solutions by kaolin: Kinetic and equilibrium studies, Appl. Clay Sci., 42: 583-590.

[19] Küncek, 1., Şener, S. (2010). Adsorption of methylene blue onto sonicated sepiolite from aqueous solutions, Ultrason. Sonochem., 17: 250-257.

[20] Hermosin, M.C., Martin, P., Cornejo, J. (1993). Adsorption mechanism of monobutyltin in clay minerals, Environ. Sci. Technol., 27: 2606-2611.

[21] Miller, S. A., Mazzini, A. (2018). More than ten years of Lusi: A review of facts, coincidences, and past and future studies, Mar Pet Geol. 90: 10-25.

[22] Jalil, A.A., Triwahyono, S., Adam, S.H., Rahim, N.D., Aziz, M.A.A., Hairom, N.H.H., Razali, N.A.M., Abidin M.A.Z., M.K.A. Mohamadiah. (2010) Adsorption of methyl orange from aqueous solution onto calcined Lapindo volcanic mud, J. Hazard. Mater., 181: 755-762.

[23] Langmuir, I. (1918). The adsorption of gases on plane surfaces of glass, mica and platinum, J. Am. Chem. Soc., 40: 1361-1403.

[24] Freundlich, H.M.F. (1906). Over the adsorption in solution, J. Phys. Chem., 57: 385-470.

[25] Lagergren, S. (1898). About the Theory of SoCalled Adsorption of Soluble Substances, Handlingar, 24(4): 1-39.

[26] Ho, Y.S., McKay, G., (1999). Pseudo secondorder model for sorption processes, Process Biochem. 34: 451-465.

[27] Song, Y.L., Li, J.T. (2009). Degradation of C.I. Direct Black 168 from aqueous solution by fly ash $/ \mathrm{H}_{2} \mathrm{O}_{2}$ combining ultrasound, Ultrason. Sonochem., 16: 440-444.

Selected and Revised Papers from The $4^{\text {th }}$ International Conference of Chemical Engineering \& Industrial Biotechnology (ICCEIB 2018) (http://icceib.ump.edu.my/index.php/en/) (Universiti Malaysia Pahang, by 1st_2nd August 2018) after Peer-reviewed by Scientific Committee of ICCEIB 2018 and Peer-Reviewers of Bulletin of Chemical Reaction Engineering \& Catalysis 